\title{
Demographic Transition and Population Ageing
}

\author{
Wan Ibrahim Wan Ahmad, PhD \\ School of Social Development, Universiti Utara Malaysia, 06010 Sintok, Kedah, Malaysia \\ wiwa@uum.edu.my \\ I Komang Astina, PhD \\ Faculty of Social Science, Malang State University, 65145 East Java, Indonesia \\ k_astina@yahoo.com \\ Budijanto, PhD \\ Faculty of Social Science, Malang State University, 65145 East Java, Indonesia \\ budijanto19@yahoo.co.id
}

\section{Doi:10.5901/mjss.2015.v6n3s2p213}

\begin{abstract}
This article discusses the findings of a literature review on older persons globally. In recent years the number of older persons aged 60 years and older is growing worldwide. Declining in birth and mortality rates are said to be the main contributors to this new phenomenon. Life expectancy of general population has also increased, and thus the number of older population in society increased. Although all nations in the world are experiencing the growth of older population, developed countries has a relatively large portion of this population in their population structure. The purpose of this article is analyzing the process of demographic transistion that produces the growth of older person world wide. In particular, it describes the growth of older population globally with particular emphasis on the proportion of older population over the years, distribution of older population, and rate of growth of this older population. By using a secondary analysis, various sources related to older persons at international level are reviewed. This paper highlights that the proportion of older population has increased, it has distributed unevently, and the growth rate of older population is higher as compared to the growth of the total population globally.
\end{abstract}

Keywords: Older person; Life expectancy; developmental process; Population growth; Industrialization

\section{Introduction}

This article reviews a range of the published materials of a literature review from various sources on older population globally. In particular, it analyzes the process of demographic transistion that produces the growth of older person worldwide. Older person has been a category of population that reach certain age in his/her developmental process. Although older persons is a commonly used concept in everyday conversation, there is no general agreement at what age a person becomes old. Despite there are many measures have been used to determine when a person becomes old, chronological aging, that is the definition of aging on the basis of a person's years from birth is the most accepted measure to determine old age. Readings on various sources of published materials on ageing, we noticed that older person has been increasing very rapidly throughout the world. Many countries, over the past three decades, have shown clear evidence that their population is at the late stage of demographic transition.

People are now living longer because life expectancy of the majority of the world population is increasing. It represents a success story of medical, social and economic improvement over disease. Some years back, population ageing was only a concern of developed countries in Europe, North America, and East Asia as they had already completed their demographic transition, but today it has become a global phenomenon, and demographers see that the world now is ageing. In other words, the world now has a luxury of ageing. Very soon, for the first time in demographic history, it is estimated that people aged 65 years and older will outnumber children under age 5 . It was also estimated that older population is growing at a faster rate than the total population in all regions of the world (United Nations, 2001a). United Nations (Kinsella, 2007) has estimated that between 2005 - 2030, the percent change in population globally for all ages is $27 \%$, but for the aged $65+$ is $104 \%$, while those aged $85+$ and $100+$ is estimated to be $151 \%$ and 
$431 \%$ respectively.

\title{
2. Objective of the Study
}

This article outlines the demographic transition and population aging worldwide. In particular, it analyzes:

(1) The process of demographic transistion that produces the growth of older person;

(2) Demographic transition and population aging, and

(3) Population aging worldwide.

\section{Literature Review}

It is clear that the process of demographic transistion has reshaped the age structure of the population in most region and has produced the growth of older person worldwide (United Nations, 2001b). The world's population is now aging at an unprecedented rate, and as we move through the first decade of twenty-first century, population aging has emerged as a major demographic trend worldwide (Kinsella and Wan He, 2009). Before the 20th century not many people survive into old age that could be categorized as old person. At that time life expectancy of many people was very low. Today, life expectancy of the majority of the population is increasing. Couple with the declining in birth as well as mortality rate has resulted the increasing in number and proportion of older population, a term used to refer to the population ageing. Population ageing is basically, refers to the increasing proportion of older persons, and at the same time the decreasing of younger persons in the population structure. Although the increasing of this category of population has long been recognized in developed countries, it is only recently that the issue has been realized in developing countries. Before 1980s, many government of developing countries tend to perceive that population ageing was an issue that concerned developed countries only (Ogawa, 1992). Now the population ageing has become an international concerned. Recognizing the number and percentage of older persons are increasing in all societies throughout the world, and the world population is ageing, United Nations has convened the World Assembly on Ageing in Vienna in 1982 to raise attention of public and policymakers alike the fact that all nations in the world are growing older and to discuss issues resulting from the ageing of population (Ogawa, 1992). Through this assembly, the action plan, i.e the Vienna International Plan of Action, was agreed to be adopted to raise awareness of the government, policy makers, as well as individuals of all ages on the consequences of population ageing. Following the Vienna International Plan of Action, all countries are encouraged to give priority and serious attention on research related to older population. The Plan of Action, particularly reccomended that:

\begin{abstract}
"International exchange and research co-operation as well as data collection should be promoted in all fields having a bearing on ageing, in order to provide a rational basis for future social policies and action. Special emphasis should be placed on comparative and cross-cultural studies on ageing. Interdisciplinary approaches should be stressed (United Nations, 1982)"
\end{abstract}

Following the assembley, the process and consequences of the ageing of population have received worldwide attention. At regional level, countries in Asia and the Pacific in a conference, i.e the Third Asian and Pacific Population Conference held in Colombo in 1982, calls upon all member states to increase awareness on the implication of the ageing of population, include to increase research efford on the implication of population ageing in society as well as to explore alternative approach for the maintainence the welfare of older persons, family as well as community. The International Conference on Population (1984) also stated that the ageing of population has become an important issue for developed countries, and following the declining in fertility rate in this region, it will also become an important issue for developing countries as well. The conference has recomended steps need to be taken by countries to analyze the issue of population ageing, particularly its implication on development, social service, health maintainence and related implication (United Nations, 1987). In an atempting to raise awareness of the governments and individuals on the implications of the ageing of population, the Second World Assembly on Ageing was held in Madrid in 2002. United Nations has also adopted the year 1999 as the International Year of Older Persons.

\section{Materials and Method}

The present paper utilizes the existing published materials as its main devices. In other words, it uses a content analysis to discuss the objectives of the study. Content analysis is defined as any technique for making inferences by objectively 
identifying specific characteristics of messages (Holsti, 1969; Shaughnessy \& Zechmeister, 1990). Content analysis is a powerful tool to help researcher examining certain information contained in any written documents. For Neuman (2011), content analysis is a technique for examining the content or information and symbols contained in written documents. Content analysis can discover and document specific features in the content of a large amount of material (Neuman, 2011). For Kart (1990) secondary analysis is any technique that describes a reanalysis of data produced by someone elze for other purpose.

As the number of older population continues to increase, the need to collect information of demographic aging increases. Information on older population worldwide now can be assessed from a wide range of published materials, whether from government agency, such as United Nations, or from various indvidual scholars. There is no doubt that all these information is very usefull if we are to discuss older persons globally. Thus, content analysis or secondary analysis is suitable for papers discussing such published materials.

Information on the demographic transition in this paper is a result of extensive reading on secondary sources from United Nations and other related sources. From secondary analysis conducted, a wide range of published materials that have been collected and published by other researchers have been analyzed. Most of the data are taken from United Nations (various years), Kinsella and Teuber (1993), Kinsella and Wan He (2009), as well as various sources related to older persons in Asia and the Pacific. In addition, data from Population Ageing in Asia, Asian Population Studies Series No. 108 (United Nations, 1991) are also important elements. Through these materials, information on older person has been reviewed and discussed.

\section{Results and Discussion}

\subsection{Demographic Transition}

Demographic transition is a demographic concept which is in general refers to the sequence of changes in population growth, particularly in terms of two demographic variables, i.e death and birth rates over time. These changes are particularly happen as a country develops from an agriculture to an industrialized economic system. Thus, according to this definition, demographic transition is a by-product of a modernization process. In early demographic history, birth rate, had only slightly exceed death rate, producing slow growth of population. Population growth at this period was very slow. Demographers agree that this pattern of population growth was the case for most of human history until about A.D 1750 (Getis, Getis and Fellmann, 1985). It took from approximately A.D 1 to A.D 1650 for the population to increase from 250 million to 500 million. This growth of population represent the first stage of demographic transition. In this stage, the population growth is characterized by a long peride of doubling time, and the increase was not steady because of wars, famines, and other disasters (Getis, Getis and Fellmann, 1985).

World demographic transition enters the second stage when the industrialization took place in Western Europe about 1750. In the second stage, population growth is marked by declining death rates accompanied by continuing high birth rates. Due to the facts that advances in medical and sanitation practices as well as rising in per capita income, the death rates are falling at this period. Life expectancy of the population was also increased. Birth rates do not fall as son as death rates as large families are considered advantageous (Getis, Getis and Fellmann, 1985). Most couples aim to have as many children as possible because children can contribute to the family, even by starting to work at early age and by supporting their parents in their old age. Most countries in developing countries are now at this stage of demographic transition.

When a nation eccelerates her industrialization, urban life begins to be a way of life. The third stage of demographic transition started when birth rates started to decline as people begin to control the number of birth (Getis, Getis and Fellmann, 1985). As many people moved to urban áreas, the advantageous of having many children as in an agrarian society has become not so evident. The costs of raising children rose, and many people started to see their children as economic liabilities rather than assets. The main demographic event in this period is the population size begins to slow down.

Demographic transition ends with the fourth stage. At this stage, high birth and high death rates are replaced by low birth and low death rates. In some countries like Germany, Italy and Japan, birth rates have droped well to below replacement level. In general most countries within developed nations are in this stage. As the birth and death rates are very low, it produces very slow population growth, and even there are some countries in Western Europe have negative growth of population growth, indicating that the death rates are higher than the birth rates. 


\subsection{Demographic Transition and Population Ageing}

Demographic transition and population ageing are two unsaparable concepts. Population ageing is a by-product of the process known as demographic transition. The process of population ageing is primarily determined by fertility as well as mortality rate, where population with high fertility tend to have low proportions of older persons and vise versa (Kinsella and Teuber, 1993). As every country has been in different stage of demographic transition, the proportions of older person differ significantly across countries. Demographic transition occurred in developed countries due to the declining in birth rates, couples with declining in mortality rates that started in the eighteenth century, promotes an increasing of older persons worldwide. Thus, developed countries generally, in a more advanced stage of the demographic transition, and their proportions of older persons are to remain significantly higher than in the less developed regions over the next several decades (United Nations, 2001a). Developing countries that has experiencing early declining in fertlity rates also experiencing rapid increases of older population.

Starting in developed countries, population ageing is becoming a distinct phenomenon in developing countries in recent years. Demographers and gerontologists view the phenomenon of increasing in older population as a population ageing. As far as it can be traced, demographic records clearly show that the phenomenon of population ageing, which is also known as demographic ageing or societal ageing in developed countries, has started to be seen as early as 1865. But it took about hundreds of years for developed countries to double their population aged 65 years and older. France, for instance, took 115 years from 1865 to 1980, and it took 85 years for Sweden from 1890 to 1975 to raise this population from $7 \%$ to $14 \%$ (Kinsella, 2007). In developing countries, the phenomenon of population ageing has only started to become a distinct phenomenon in the twenty-first century. Even though this phenomenon is just a new one, it will not take too long for developing countries to raise this population from $7 \%$ to $14 \%$. Singapore, Colombia, Brazil, as well as Thailand and some other developing countries will take only two or three decades to double their older population from 7\% to 14\% (Kinsella, 2007).

Why does the older population in a population structure increase? Normally, a population, or age structure can only be changed by the changes in fertility and mortality rates. If the fertility rates decline, the size of most recent birth cohorts will reduce as compared to the previous birth cohorts in any age structure. This change is eventually reducing the size of younger age groups relative to that of the older age groups. Thus the shifting of high dearh and birth rates to low death and birth rates in a sequence of change, a process called demographic transition, produces population ageing because the proportion of older population within an age structure increases (de Souza, 1990; Quadagno, 1999). In other words, the population ageing occurs as the demographic transition of the population progress over time. To answer why older population increases clearly, it is useful to briefly examine the so-called demographic transition that occurs in a particular population. Johnson and Falkingham (1992) highlighted four stages in the demographic transition that bring about the ageing of the population:

1. An initial stage: High level of fertility and mortality, and low population growth. The population has a youthful age profile with a high proportion of the young.

2. Second stage: Mortality rates begins to fall while fertility level remains at a high level. If the improvement in mortality is concentrated at younger ages then the population structure may become younger at this stage.

3. Third stage: Fertility rates also begin to decline. The rate of population growth starts to tail off and the proportion of the elderly population begins to increase.

4. Final stage: Fertility and mortality level reach equilibrium. Population growth is again low, and could be approaching zero. The age structure of the population stabilizes with a relatively high proportion of the elderly people.

\subsection{Population Ageing}

Over the years, older population is growing globally. According to one estimate (United Nations, 1991) there were 7.1\% population aged 65 years and older in the entire world in 2005. As the world has $7 \%$ or more population aged 65 years and older in 2005, the entire world is said to be getting the status of aged society in that year. United Nations categorized a society as an aged one when its population aged 65 years and older in the population structure amounting $7 \%$ or more (Masitah dan Nazileh 1988). While developed countries as a whole had been categorised as an aged sosiety since 1950, developing countries as a whole will only be categorised as an aged society around 2020 when its older population aged 65 years and older reach $7.0 \%$.

The number of older persons in the population is increasing in almost all countries (Fernandez and Forder, 2010). In 1950, as estimated by United Nations (2001), there were 205 million persons aged 60 years and older in the world. At 
that time only 3 countries had more than 10 million people aged 60 years and older, namely China (42 million), India (20 million), and the United States of America (20 million). In 2000, the number of this population had more than trippled to around 607 million, and in that year, the number of countries with more than 10 million has increased to 12, including 5 countries had more than 20 million older persons, namely China (129 million), India (77 million), the United States of America (46 million), Japan (30 million), and the Russian Federation (27 million).

It is projected there will be nearly 2 billion people aged 60 years and older in 2050, and 33 countries are expected to have more than 10 million older people aged 60 years and older, including 5 countries with more than 50 million older people, namely China (437 million), India (324 million), the United States of America (107 million), Indonesia (70 million), and Brazil (58 million). The annual growth rate of older persons has also increased. In the period 1950 - 1955, the annual growth rate globally was $1.8 \%$, only slightly higher than the annual growth rate for total population. Currently, the annual growth rate of the total population is $1.2 \%$ while for older persons is $1.9 \%$. The difference is expected to become larger (United Nations, 2001b).

Today although population ageing is a worldwide phenomenon, and developed nations have relatively high proportions of older population, but the most rapid increases are in developing countries (Kinsella and Wan He, 2009). In other words, developing countries are ageing very rapidly, and at a more rapid rate than in the developed world (Kinsella and Teuber, 1993). The majority of the increasing has been in developing countries. Developing countries also sheltered the majority of the world older population today. Eighty-one percent of the world's net gain of older persons aged 65 years and older from July 2007 to July 2008 occured in developing countries.

In 2000, from 607 million people aged 60 years and above, 232 million resided in developed countries, while 375 million in developing countries. In 2025, the number of older persons aged 60 years and older will be 1180 million, and about 344 million from that figure will be in developed countries, while developing countries sheltered 836 million of the aged populations (United Nations, 2001a). According to United Nations (2001), developing countries is a home for the majority of older persons. In 1950 older persons aged 65 years and older constituted only $49.0 \%$ in advanced countries, while $51.0 \%$ resided in developing countries. In 2000 developed countries have sheltered about $40.7 \%$ of older persons as compared to $59.3 \%$ in developing countries. Developing countries will remain the home for the majority of the world older populations, and 80\% of this populations will be resided in developing countries in 2050.

\section{Conclusion}

This present paper discussed the growth of older population globally. The number of older persons aged 60 years and older is growing worldwide. The world's population now not only ageing, but it is ageing at an unprecedented rate. This growth is particularly related to what we called demographic transition that occurred worldwide. Demographic transition has promoted an increasing of older person worldwide. Because of the transition of high mortality and fertility rates to low mortality and fertility rates, demographic transition has become a worldwide phenomenon. This transition produces changes in population structure. Every country right now is at different stages of the demographic transition. As developed countries as a whole has completed their demographic transition, they have high proportions of older population. As every country in developing countries is now at different stage of demographic transition, the process of population ageing is not the same, and thus, the proportions of older population differ significantly across countries. Generally, a country with higher stage of demographic transition will has a higher proportion of older population. Population ageing that has long been started in developed countries will be soon become a distinct demographic phenomenon in developing countries as well. Thus, very soon we will be living in an ageing world where at that time there will be more older people in society than the younger ones.

\section{References}

De Souza, A. R. (1990). A geography of world economy. Ohio: Merrill Publishing. Fernandez \& Forder, (2010). Ageing societies: Challenges and opportunities. Bupa Health Pulse 2010. www.bupa.com/healthpulse. Getis, A., Getis, J., \& Fellmann, J. (1985). Human geography. New York: Macmillan.

Holsti, O. R., (1969). Content analysis for the social sciences. Massachusett: Addision-Wesley Johnson, P. \& Falkingham, J. (1992). Ageing and economic welfare. London: Sage Publication Quadagno, J. (1999). Ageing and the life course. Boston: McGraw-Hill Company.

Kart, C. S., 1990. The realities of ageing: An introduction to gerontology. Boston: Alan and Bacon

Kinsella, Kevin \& Taeuber, Cynthia M. (1993). An ageing world II. U.S. Bureau of the Census, international population reports P95/92-3. Washington D.C: U.S Government Printing.

Kinsella, K. (2007). Global ageing into the $21^{\text {st }}$ century, paper presented at In-situ trainning on Demographic Ageing, INIA and Universiti 
Putra Malaysia, August.

Kinsella, K. \& Wan He. (2009). An ageing world: 2008. U.S. Bureau of the Census, international population reports P95/92-3. Washington D.C: U.S Government Printing.

Masitah Mohd. Yatim \& Nazileh Ramli. 1988. Socio economic consequences of the ageing of population survey 1986: Malaysia country report. Kuala Lumpur: LPPKN.

Neuman, W. Lawrence, (2011). Social research methods. Boston: Pearson

Ogawa, N. (1992). Resources for the elderly in economic development. In Hal L. Kendig et al. (eds.), Family support for the elderly. The international experience. Oxford: Oxford University.

Shaughnessy, J. J. \& Zechmeister, E. B. (1990). Research methods in psychology. New York: McGraw-Hill.

United Nations. 1982. Report of the world assembly on ageing, Vienna, 26 July to 6 August 1982. United Nations: New York.

United Nations. 1987. Population ageing: Review of emerging issues. Asian population studies series No. 80. Bangkok: Economic and Social Commission for Asia and the Pacific.

United Nations. 1991. Sex and age distributions of population. New York: Department of International Economics and Social Affair.

United Nations. 2001a. World populationprospect: The 2000 revision, Volume 1: Comprehensive Tables. New York: United Nations Publications, Sales No. E. 01. XIII.8.

United Nations. 2001b. World population ageing: 1950 - 2050. New York: Department of Economic and Social Affairs, Population Division. 